\title{
R\&D investment intensity, green energy technology innovation and construction firm growth performance
}

\author{
Huanxing $\mathrm{LIU}^{1 *}$ \\ ${ }^{1}$ School of Management, Tianjin University of Technology, Tianjin 300384, China
}

\begin{abstract}
Based on the data of listed construction companies in the jewelry manufacturing industry in 1994 from 2014 to 2017 , this article uses the generalized least squares method to analyze the relationship between green energy technology innovation, construction enterprises' growth performance and R\&D investment intensity, and explores the impact of green energy technology innovation on construction enterprises' growth performance and analyzes the moderating effect of R\&D investment intensity. The empirical results show that green energy technological innovation has a significant positive impact on construction enterprises' growth performance. The intensity of R\&D investment has a significant negative regulatory effect on the relationship between green energy technological innovation and construction enterprises' growth performance
\end{abstract}

\section{Introduction}

Since the 18th National Congress of the Communist Party of China, the concept of "green mountains and green mountains are golden mountains and silver mountains" has promoted the development of China's economy in a green and sustainable direction. Nowadays, more and more enterprises rely on technological progress and innovation to improve their performance, however, the research on the relationship between green technological innovation and enterprise performance has not reached a consistent conclusion. According to the existing research ${ }^{[1]}, \mathrm{R} \& \mathrm{D}$ investment, as an important means of technological innovation, will affect the growth performance of enterprises. Therefore, it is necessary to analyze the relationship among R\&D investment, green technology innovation and enterprise growth performance. This paper studies the relationship between green technology innovation and enterprise growth performance, and also discusses the moderating effect of R\&D investment intensity on the relationship between them.

\section{Theoretical basis and research assumptions}

\subsection{The impact of green technology innovation on enterprise growth performance}

According to the resource-based theory, valuable, scarce and not completely imitated resources can keep the competitive advantage of enterprises ${ }^{[2]}$. By implementing the green innovation strategy, enterprises can establish a green image, which is conducive to the long-term development of enterprises. This paper argues that green technology innovation has a positive impact on the growth performance of enterprises. Secondly, enterprises can combine ecological protection with their own development, actively develop diversified management strategy, and better transform ecological benefits into economic benefits. Finally, the enterprise actively implements the green technology innovation strategy, and promotes its own green, low-carbon and sustainable development with technological progress Based on the above research, this paper puts forward the following assumptions:

H1: Green technology innovation has a significant positive impact on enterprise growth performance.

\subsection{The regulatory role of $R \& D$ investment intensity}

More and more scholars began to pay attention to the impact of $R \& D$ investment and $R \& D$ investment intensity on firm innovation or firm performance. Existing research shows that $R \& D$ investment activities have a positive impact on enterprise innovation performance ${ }^{[1]}$. First of all, if the enterprise excessively increases the investment of R\&D funds, it may cause investment redundancy, which will bring low utilization rate of $R \& D$ investment funds and lower enterprise performance. Secondly, the excessive investment of $R \& D$ personnel leads to the unreasonable structure of employees and the failure to give full play to the value of employees. Based on the above research, this paper puts forward the following assumptions:

H2: R\&D investment intensity has a significant negative regulatory effect on the relationship between

* $\overline{\text { Corresponding author: huanxingliu } @ 126 . c o m ~}$ 
green technology innovation and enterprise growth performance.

\section{Research and design}

\subsection{Sample selection and data sources}

In this paper, listed manufacturing companies from 2014 to 2017 are selected as the research objects of green technology innovation. According to the industry classification of CSRC in 2012, this paper selects chemical raw materials and chemical products manufacturing, chemical fiber manufacturing and pharmaceutical manufacturing as research samples, and obtains the data needed by this research through CSMAR database, and finally obtains the unbalanced panel data of 94 listed companies by eliminating the companies with incomplete information disclosure and ST companies. Among them, the data of green invention patent and green utility model patent are obtained by the author by downloading the full patent text of the patent database of the State Intellectual Property Office and manually sorting it out; Other data such as enterprise growth performance, technical capability, enterprise scale and asset-liability ratio come from CSMAR database.

\subsection{Variable measurement}

\subsubsection{Explained variable: enterprise growth performance}

In this paper, the research of Coad et al,(2008) ${ }^{[3]}$ is used for reference, and the growth performance variables of enterprises are measured by calculating the sales growth of enterprises (the logarithmic difference between the sales of this year and the sales of last year).

\subsubsection{Explanatory variable: green technology innovation}

Based on the text analysis method of Wang $\mathrm{Xu}$ et al, $\left(2018^{[4]}\right.$, this paper determines eight keywords: environmental protection, low carbon, pollution, energy saving and emission reduction, carbon emission, waste recycling, sustainability and new energy; Identify the number of green invention patent applications and the number of green utility model patent applications through keyword search; Third, the full text is screened and the applications unrelated to green technology innovation patents are eliminated.

\subsubsection{Regulated variable: $R \& D$ investment intensity}

Based on the research of Yang Lin et al,(2018) ${ }^{[5]}$, this paper uses the relative index method to measure the R\&D investment intensity, that is, the ratio of $R \& D$ investment to operating income is used to measure the R\&D investment intensity.

\subsubsection{Control variable}

In this paper, the ratio of the number of researchers to the total number of employees is used to measure the technical ability, and the ratio of the total debt to the total assets at the end of the period is used to measure the asset-liability ratio.

\subsection{Empirical analysis methods}

In order to avoid heteroscedasticity and autocorrelation, this paper uses Stata15.0 software and adopts generalized least square method to perform hierarchical regression on sample data.

According to the research of Filiou et al, $(2018)^{[6]}$, the patent application date is closer to the innovation time than the patent authorization date. Therefore, this paper uses patent application date to count the number of green patents. This paper constructs the following measurement model:

$$
\begin{gathered}
\text { Growth }_{i, t}=\alpha+\beta G T_{i, t}+\sum \gamma_{i} \text { Control }_{i, t}+\varepsilon \\
\text { Growth }_{i, t}=\alpha+\beta G T_{i, t}+\theta_{1}(T G \times R D)_{i, t}+\sum \gamma_{i} \text { Control }_{i, t}+\varepsilon \\
\text { Growth }_{i, t}=\alpha+\lambda \text { Growth }_{i, t-1}+\beta G T_{i, t-2}+\sum \gamma_{i} \text { Control }_{i, t-2}+\varepsilon(3) \\
\text { Growth }_{i, t}=\alpha+\lambda \text { Growth }_{i, t-1} \beta G T_{i, t-2}+\theta_{1}(T G \times R D)_{i, t-2}+ \\
\sum \gamma_{i} \text { Control }_{i, t-2}+\varepsilon
\end{gathered}
$$

This paper draws lessons from the research of Zhang Rui, etc., and adopts the data of explaining variables, controlling variables and regulating variables lagging behind for two periods when regressing the growth performance of enterprises, At the same time, it also considers the data of the growth performance lagging behind for one period, and establishes models (3) and (4). Model (3) examines the relationship between green technology innovation and enterprise growth performance, and model (4) examines the moderating effect of R\&D investment intensity on the relationship between green technology innovation and enterprise growth performance.

\section{Empirical analysis}

\section{1 regression analysis}

Table 1 reports the hierarchical regression results of green technology innovation, R\&D investment intensity, lag 2 control variables and lag 1 enterprise growth performance. From model 2 in table 1, it can be seen that the regression coefficient of growth performance in the first period behind is 0.142 ( $\mathrm{P}<$ 0.01 ), and that of green technology innovation in the second period behind is $0.003(\mathrm{P}<0.05)$, Hypothesis 1 is verified. Model 3 in Table 1 verifies the moderating effect of R\&D investment intensity with lag 2 on the relationship between green technology innovation with 
lag 2 and enterprise growth performance, and hypothesis 2 is verified.

Table 1. Regression analysis results of green technology innovation on enterprise growth performance after adding time effect.

\begin{tabular}{cccc}
\hline Variable & Model 1 & Model 2 & Model 3 \\
\hline Size $e_{t-2}$ & $-0.728^{* * *}$ & $-0.0076^{* * *}$ & $-0.072^{* * *}$ \\
$T C_{t-2}$ & $0.178^{* *}$ & $0.152^{*}$ & $0.200^{* * *}$ \\
Lev $_{t-2}$ & -0.028 & -0.096 & $-0.200^{* *}$ \\
Growth & $0.151^{* * *}$ & $0.142^{* * *}$ & $0.072^{* * *}$ \\
$G T_{t-2}$ & & $0.003^{* *}$ & $0.023^{* * *}$ \\
$R D_{t-2}$ & & & $0.790^{* *}$ \\
$(G T \times R D)_{t-2}$ & & $-0.410^{* * *}$ \\
constant term & $1.740^{* * *}$ & $1.812^{* * *}$ & $1.727^{* * *}$ \\
Wald chi $^{2}$ & $40.22^{* * *}$ & $323.95^{* * *}$ & $3589.16^{* * *}$ \\
\hline
\end{tabular}

\subsection{Robustness test}

In this paper, with the help of Stata15.0 software, the generalized least square method is used to carry out hierarchical regression analysis on each variable data. The specific hierarchical regression analysis results are shown in Table 2, which proves the robustness of the test results.

Table 2. Regression analysis results of green technology innovation on enterprise growth performance after adding time effect.

\begin{tabular}{cccc}
\hline Variable & Model 1 & Model 2 & Model 3 \\
\hline Size $_{t-2}$ & $-0.728^{* * *}$ & $-0.061^{* * *}$ & $-0.074^{* * *}$ \\
$T C_{t-2}$ & $0.178^{* *}$ & $0.164^{* *}$ & $0.214^{* * *}$ \\
Lev $_{t-2}$ & -0.028 & -0.122 & $-0.199^{* * *}$ \\
Growth & $0.151^{* * *}$ & $0.155^{* * *}$ & $0.070^{*}$ \\
$G T_{t-2}$ & & $0.005^{* *}$ & $0.024^{* * *}$ \\
$R D_{t-2}$ & & & 0.648 \\
$(G T \times R D)_{t-2}$ & & & $-0.421^{* * *}$ \\
constant term & $1.740^{* * *}$ & $1.493^{* * *}$ & $1.763^{* * *}$ \\
Wald chi $^{2}$ & $40.22^{* * *}$ & $592.34^{* * *}$ & $1221.27^{* * *}$
\end{tabular}

\section{Research conclusions and discussions}

Based on the data of listed companies in GEM manufacturing industry from 2014 to 2017, this paper empirically analyzes the impact of green technology innovation on enterprise growth performance, and discusses the moderating effect of R\&D investment intensity on the relationship between green technology innovation and enterprise growth performance from the perspective of R\&D investment intensity. The research results are as follows:

(1) Green technology innovation has a significant positive impact on the growth performance of enterprises. First, innovation is the driving force of development. Focusing on green new technologies and new products can improve the utilization rate of enterprises' own resources and thus reduce their production costs. Second, green technology innovation can inject new development impetus into enterprises and achieve sustainable development of enterprises. Third, enterprises should actively respond to the call of the government and improve their performance by implementing green technology innovation.

(2) R\&D input intensity negatively affects the relationship between green technology innovation and firm growth performance. The possible reasons are as follows: First, increasing R\&D investment is not conducive to improving the overall performance of enterprises. Secondly, from input to output, it may bring some cost increase to enterprises in the early stage of research and development. Finally, investing more capital and personnel in $\mathrm{R} \& \mathrm{D}$ may bring higher operating risks to enterprises. 


\section{References}

1. ZENG Deming, SU Ruirui, WEN Jinyan. R\&D Investment and Firm Innovation Performance- A Study on the Mediating Role of R\&D Team's Network Structure[J]. Science and Technology Management Research, 2015,35(18):71-77.

2. Barney J B. Firm Resources and Sustained Competitive Advantage[J]. Advances in Strategic Management, 1991, 17(1):3-10.

3. Coad A, Rao R. Innovation and firm growth in hightech sectors: A quantile regression approach[J]. Open Discussion Papers in Economics, 2007, 37(4):633648.

4. WANG $\mathrm{Xu}, \mathrm{CHU} \mathrm{Xu}, \mathrm{WANG}$ Fei. Green Technology Innovation and Enterprises' Optimal Dynamic Configuration of Financing Contracts An Empirical Study Based on Panel Data of the Listed High-tech Manufacturing Companies[J]. R\&D Management, 2018, 30(06):12-22.

5. Yang Lin, Duan Muyu, Liu Juan, et al.. Top management team overseas experiences, R\&D investment intensity and enterprise innovation performance $[\mathrm{J}]$. Science Research Management, 2018, 39(06):9-21.

6. Filiou D, Massini S. Industry cognitive distance in alliances and firm innovation performance $[\mathrm{J}]$. R\&D Management, 2017. 